\title{
THE ANALYSIS OF DRIVERS' REACTION TIME USING CELL PHONE IN THE CASE OF VEHICLE STABILIZATION TASK
}

\author{
VIDAS ŽURAULIS, SAULIUS NAGURNAS, ROBERTAS PEČELIŪNAS, VIDMANTAS PUMPUTIS, \\ and PAULIUS SKAČKAUSKAS
}

Vilnius Gediminas Technical University, Vilnius, Lithuania

Department of Automobile Engineering

\begin{abstract}
Objectives: The article analyzes the driver's psychophysiological qualities such as complex reaction and individual ability to control the vehicle that has suddenly lost its stability. The comparative analysis of the duration of reaction time was performed to assess the negative influence of speaking on a phone and driving with one hand. Material and Methods: The experimental research was carried out on special training grounds with the road surface having low adhesion coefficient, where sudden lateral vehicle destabilization was caused by the moving plate mounted on the road surface. The vehicle onboard equipment was used for identifying the difference between the destabilization moment and the responsive driver's steering wheel movement which in this research was assumed as the reaction time. Results: Statistical methods of research applied for the analysis of results showed high probability that the driver's actions would be significantly late in controlling a vehicle. When stabilizing a vehicle movement, the complex reaction time of a vehicle driver speaking on a mobile phone is increased by $18.1 \%$ as compared with the conventional driving by a driver not speaking on a phone. Conclusions: The risk of using the phone depends on the driver characteristics, traits and attitudes that affect the level of their experienced dangers, and the intensity of using mobile phones and driving. Speaking on a phone while driving increases the driver's reaction time and mental workload, and changes his or her visual overview ability as well as understanding of the situation. Int J Occup Med Environ Health 2018;31(5):633-648
\end{abstract}

Key words:

Driver, Cell phone, Reaction time, Statistical analysis, Psychophysiology, Vehicle stabilization

\section{INTRODUCTION}

Some of the periods in the driver's performance, especially when driving at high speeds, take place under difficult conditions. The quality of driver's actions in such cases depends on the speed and accuracy of counter-reactions to various stimuli. In response to stimuli, the driver performs a variety of actions: presses the brake or the accelerator pedal, turns the steering wheel or shifts gears. Each sensory-motor reaction comprises hidden (latent) period of reaction - the time from the beginning of stimulus to the beginning of the response action, and the period of implementation of the motor action - the time from the beginning to the end of the responsive action. The average time of a simple hidden reaction to the light signal time is $0.2 \mathrm{~s}$, and to the audible signal $-0.14 \mathrm{~s}$. The overall reaction time (the sum of the hidden reaction time and the responsive action time) varies greatly, depending on the time required to perform a responsive action. For example, the total sum of times of

Received: September 8, 2017. Accepted: December 18, 2017.

Corresponding author: Vidas Žuraulis, Vilnius Gediminas Technical University, Department of Automobile Engineering, J. Basanavičiaus g. 28 , 03224 Vilnius, Lithuania (e-mail: vidas.zuraulis@vgtu.lt). 
reaction of the light stop signal, and moving the foot from the accelerator pedal on the brake pedal is $0.4-0.6 \mathrm{~s}$ [1]. Reaction time is one of the key factors indicating the driver's ability to act in an emergency situation. The time and correctness of decision in emergency situation, and the speed of implementing the driver's actions often determines whether the situation will result in a traffic accident or not. Most of the research results indicate that the driver's reaction time ranges 0.4-1.5 s. Unfortunately, the average reaction time is not stable and constant in size, even for the same driver. Many factors have an impact on the average reaction time. Some of them may be improved but others depend only on individual characteristics of the driver's body [2].

Reaction time usually means the duration of the occurrence of risk on the road, till the end of implementation of the actions to avoid danger. The driver's reaction time comprises 2 components: sensory and motor, which means that the total duration consists of 2 times, which are not far from unambiguous. The first time is sensory, equal to the sum of time needed to perceive the traffic situation and the risks it poses (or an endangering object), and the time needed to make a decision on how to avoid danger. The second time is motor, equal to the time needed to carry out the vehicle control steps to ensure the realization of the decision made in the first step. The motor reaction time remains relatively stable for each driver [3,4].

Each sensory-motor reaction has 4 psychological stages: sensory, central and motor reaction moments, and sensory-motor motion coordination (feedback). The sensor reaction moment means the perception of signal (stimulus) with human sensory organs. It lasts about $0.18-0.3 \mathrm{~s}$. It is the central reaction moment and identification and evaluation of the received signal (stimulus), choice and decision making. The stage lasts $0.2-1.5 \mathrm{~s}$ (possibly longer). The driver's reaction time increases due to anxiety, confusion, or complex traffic situation. It also depends on training, qualification level, fatigue, illness, alcohol and drug effects, psychological distress [5], sleepiness [6-8] and driver's disease, such as obstructive sleep apnea $[9,10]$. Fatigue and perceived workload may also be moderated by personality traits [11]. The total sensory-motor driver's reaction time is $0.5-2 \mathrm{~s}$ (it may be longer), the total reaction time increases from $0.25 \mathrm{~s}$ to $0.29 \mathrm{~s}$ in each of the stages. Simple sensory-motor reaction means a predictable, rapid reaction to an unexpected known signal (stimulus) performed in one movement. The sensory-motor reaction time is calculated from the beginning of the signal perception to the beginning of the rebound. The rebound reaction time is calculated from the beginning till the end of the rebound. The total reaction time is calculated from the beginning of the signal perception till the end of the rebound (the sum of sensory-motor and rebound reaction times) [3].

Complex sensory-motor reaction means rebound to unexpected and simultaneous stimuli not known in advance. It includes situations requiring to select one of several possible actions. This reaction may take place only under certain psychological processes (attention, memory and thinking, possibly accompanied by emotion). If the driver's attention is focused elsewhere and he or she does not notice the signal, his or her reaction time for decision increases [3]. The time of complex sensory-motor driver's reaction in a complicated traffic situation, under fatigue, illness, positive or negative emotions, alcohol effects, as well as for other objective reasons increases, and may be as high as 3-4 s. A small decrease in the intensity of light, compared with daylight, extends the sensory-motor reaction time by $0.6-0.7 \mathrm{~s}$, and when the lighting is less than 2 lux, the reaction time is increased to $2-3 \mathrm{~s}$. The increase in the reaction time may be explained by more time needed for the perception of the object. This must be considered in the assessment of safe distance and other values. With vehicle speeds increased up to $70-80 \mathrm{~km} / \mathrm{h}$, the sensorymotor driver's reaction increases by $0.1 \mathrm{~s}$ [2].

Sensory-motor coordination means the vehicle control, in order to prevent it driving off the road, and similar opera- 
tions carried out by sensory-motor processes. Support of vehicle travel in the desired direction is carried out by simple sensory-motor coordination - the monitoring reaction. The quality of reaction is described by the final result, which requires to have sensory-motor properties such as movement coordination. Nevertheless, the perception of senses depends on the driving experience, expertise, interests, abilities, and other characteristics, as well as the person's psychological state (mood, fatigue, excitement, etc.) [12]. In the modern world, driving is often aggravated by extra factors, like speaking on a phone. It is associated with the driver's distraction. While many countries have a ban on using a phone (for typing, reading the text, speaking), this ban is often ignored. Research is often performed: with participants using a vehicle simulator [13]; examining the statistics of a phone usage during accidents; investigating the influence of personality to the inclination to use a phone while driving.

In this study a detail review of various pieces of research about the driver's reaction time and the influencing factor of a cell phone usage is done. The experimental part analyzes the driver's reaction and the ability to control the vehicle that has suddenly lost its stability. The comparative analysis of the duration of the complex reaction was performed to assess the negative influence of speaking on a phone and driving with one hand. Statistical methods of the research applied for the analysis of results allowed to assess the impact of speaking on a phone, on the vehicle control and overall traffic safety.

\section{Review of phone usage influence on drivers behavior}

Starting with the last decade of the twentieth century, a big number of studies have been performed using a variety of experimental environments (driving simulators, test polygons, real traffic conditions), while analyzing the effects of the mobile phone use on the driver's behavior [14,15]. All of them found that the phone conversations behind the steering wheel had a negative effect on driving regardless of the type of the phone (hand-held or hands-free). Even the sound of a ringing mobile phone has a negative influence on the complex reaction time [16]. However, there are still a lot of drivers ignoring prohibitions and using mobile phones while driving [17].

Usually, 4 variables are used for analyzing the effect of speaking on a phone on the driver's behavior:

- reaction to stimuli, expressed as the average reaction time and possible errors,

- vehicle control (position in the driving lane, distance in the front, speed changes),

- vision,

- working load.

There is no consensus on the lateral controllability of the car. Haigney et al. [18] showed that the lateral controllability worsened using only hand-held phones rather than hands-free equipment. Burns et al. [19] and Alm and Nilsson [20] did not find any effect on using the phone on the stability in the driving lane. According to Törnros and Bolling [21], sideslips were bigger only during dialing.

A number of studies were carried out to evaluate the impact of telephone conversations on the mental load while driving. Mental load expresses the cumulative effect of 2 or more tasks to be carried out simultaneously. This effect may overload the driver's cognitive capacity. In general, the working load is measured with the subjective scale or physiological data records (heart rate variability). All the authors found the increase in the mental load, regardless of the type of a telephone used (handheld or hands-free system) [18,20,22-25]. The influence of conversation complexity on proper driving is also significant but all types of conversation or texting on a phone reduce drivers' attention to the road traffic events [15].

Several studies that examined the effect of telephone calls on the driver's vision showed that the driver's eyes jumped around less when looking at the object, they spent more time looking with the central area of the eye, and less time looking to the instrument panel and mirrors [23,26,27]. Re- 
carte and Nunes [28] found that engagement in 2 simultaneous tasks reduced the space area overlooked by drivers. Atlchley and Dressel [29] found that adding the speaking task greatly reduced the functional field of vision and the ability to localize peripheral information. Papadakaki et al. [14], according to their simulation study, approved the assumption that drivers adopted "virtual" safety margins in lateral position when driving and using a cell phone.

Strayer et al. [30] found that the mobile call modified the response method to the stimuli of the driving environment. Even when drivers look at objects, they do not see them because the phone conversation causes the "blindness of attention." The authors demonstrate that the telephone conversations worsen both the explicitly expressed recognition memory and the hidden perception memory. Richard et al. [31] and McCarley et al. [32] point out the effects of double-tasking to the "change blindness." These authors, using the image-flicker technique, showed that the hearing task performed simultaneously impaired the ability to detect changes in images of scenes.

The results of the research on the duration of fixation also vary. McCarley et al. [32] found the decrease in the duration of the motor eye fixation. On the contrary, Recartes and Nunes [28] showed that double tasking changed the durations of the driver's fixation - while they were longer for the task of the spatial view, no change was noted for the speaking task. McPhee et al. [33] found that fixation was longer on older people under the conditions of split attention.

The perception of the situation was also studied. It is described as the "human ability to recognize environmental elements in a given time and space, to deceive their meaning, and to foresee their condition in the near future." The authors showed that the driver's perception of the situation changed the course of the conversation [34-37].

Independent variables were used for examining the effects of writing and reading messages (SMS), while driving: writing, reading or both. Dependent variables were used: eye movements, notice of stimulus, reaction time, collisions, following the lane, speed, forward movement. A connection between the independent and dependent variables was determined. It was found that SMS reading or writing negatively affected all dependent variables. Only writing caused a similar drop as reading and writing. Only reading resulted in a lower drop and a smaller number of dependent variables $[38,39]$.

Tests were carried out with a simulator to evaluate the making of the decision to stop. Three different scenarios were used: on urban, peri-urban and highway streets. Persons were driving according to the variety of scenarios: without calling (reference), answering the call by picking the phone, using hands-free equipment and a voice control device. The evaluated characteristics included the driver's reaction time, braking acceleration, speed, and distance to the vehicle in the front. No significant difference was found for driving between the 3 phone usage scenarios. The use of hands-free equipment compared with a handheld phone does not reduce the reaction time [40]. The phone has a significantly greater negative effect on driving and the number of accidents in the city [41].

\section{Relation between phone usage and risk to get into a traffic accident}

The effect of a phone usage on the driver's reaction time and situational awareness was analyzed based on different thinking levels with hands-free and hand-held phone, using a vehicle simulator and changing the mental load by involving the driver to conversations of diverse degree of complexity (informal communication, memories and film discussion, grammar editing and correction). Research subjects were divided into 3 age groups: young, medium and elder. The reaction to road signs, sudden emergence of pedestrians was observed. A significant negative impact was found in the perception, and in remembering the road signs [42]. The medium age group was affected the least, the young people had a little higher impact, and elder had 
considerably bigger impact. The analysis of logistic regression showed that gender, age, unemployment, household income, immigrant status and risk perception were significant factors in predicting the phone use while driving $[43,44]$.

Using the phone while driving was comparable to driving under the influence of alcohol (0.8 ppm). Braking reaction increased both when holding the phone and using the headset [45]. In the United States, 25\% of accidents are caused by driver distraction. About a half of the drivers, although it is prohibited, continues to use phones [43]. The growing trend of driver distraction is observed because of a variety of new smart devices. The incidence of using the phone for SMS reading, writing, speaking is growing among drivers, despite the prohibiting laws [41]. Legal measures to address this issue are inefficient, therefore, technical means would be required. There is also a need to improve the collection of data on accidents caused by a phone usage [46]. When preparing the training programs and legislation programs, it is appropriate to also consider various psychological factors (personal attitude, standards, controls, risk perception) for which drivers use the phone [47].

However, there is conflicting data as well. A study was conducted in an attempt to link the use of the phone by drivers, accidents and the starting moment of discounts for calls during the time of the day. Sevenfold increase in the probability of the driver to receive a call after 9 p.m. was noted. Compared with the reference period, it was found that there was no corresponding change in accidents [48]. The new direction of research while using the selection effects, such as whether drivers using phones are likely to be less safe drivers, even when the phone is not used. It was found that the use of phones in the society was not constant. This result may suggest that previous studies based only on accident statistics and deriving the risk to the society from it had approximately one-third error. After adjusting the interpretation of the research by endo- geneity (personality traits), no significant effect was found on accidents using hands-free equipment or a hand-held telephone [40].

Many experimental studies have shown deterioration in driving performance during telephone calls but a lot less of epidemiological studies have been carried out in an attempt to assess whether the use of a phone while driving increases the risk of getting involved in a traffic accident. Researchers used 4 methodological approaches:

- The retrospective cohort study to compare 2 populations of drivers, one of them using a mobile phone, and the second - not using, and examining whether the use of the phone increases the risk of involvement in a collision [49-51].

- The second method compared the driver population (cases) involved in accidents, with the reference driver population (cases) not involved in accidents, and assessed whether the number of mobile phone users among the fatalities is higher [52].

- The third method analyzed the population of mobile phone users involved in collisions, and the relation between the telephone user activities and involvement in traffic accidents, followed by cross-examination of the cases in which each subject is like his own reference [49,53,54].

- The last method is used to analyze the population of the victims of traffic accidents, and evaluate whether the percentage share of the mobile phone users is different for various types of accidents [55,56].

These studies differ not only by the methodological techniques but also by the size of the population sample (from hundreds to tens of thousands of people) and by the investigated collision type (fatal accidents, traffic accidents only causing substantial damage to property, traffic because of error, etc.).

These studies suggest that mobile phone users faced a $38 \%$ greater risk of being involved in a road accident than non-users. Taking into account additional interfering 
variables (mileage and driving habits), the adjusted relative risk of mobile phone users in respect of non-users to be involved in at least 1 accident/year is reduced to 1.11 for men and 1.22 for women [50]. According to Wilson et al. [51], drivers, who have been found using mobile phones, cause $16 \%$ greater risk of being involved in a traffic accident because of error than non-users, and these differences are not significant for men (1.10) but high for women (1.31).

Laberge-Nadeau et al. [50] pointed out the existence of a dose-reaction relationship between the frequency of using a mobile phone and the traffic accident risk. Intensive users of mobile phones have the adjusted relative risk of at least "two" in comparison with minimum users having the intensity of traffic accidents similar to non-users. The same observation was also performed by Violanti and Marshal [52]. In their study, the use of a mobile phone for more than $50 \mathrm{~min} / \mathrm{month}$ is associated with a 5.59 times greater risk of collisions as compared to people who do not use mobile phones at all.

Comparing the drivers' telephone activity during the few minutes before the accident with the yesterday's telephone activity, Redelmeier et al. [53] found that the mobile phone activity while driving accounted for the four-fold increase in the relative risk of collisions (4.3). Laberge-Nadeau et al. [49] applied the cross-case study approach used by Redelmeier for Quebec data. They showed that a mobile phone use on the day of the traffic accident was $55 \%$ higher than the average daily usage, with a relative risk increase of 5.13 times. McEvoy et al. [54] obtained similar results: a driver's use of a mobile phone up to $10 \mathrm{~min}$ before the traffic accident was linked to 4 times (4.1) higher accident probability.

Analyzing reports of traffic accidents, Violanti [55] showed highly associated increased risk of a fatal collision with a phone use or its presence in a traffic accident: the risk when using a mobile phone is 9.29, while just in the presence of a phone is 2.11. In the Norwegian Sagberg [56] study, $0.66 \%$ of guilty drivers and $0.3 \%$ of innocent drivers confessed about using a mobile phone during the traffic accident. It has been estimated that mobile phones are used in $0.86 \%$ of the accidents which is $72 \%$ more than the expected rate, estimated by the "induced exposure" method.

In addition, Sagberg [56] found that the rear-end collision was the most common type of accidents, caused when speaking on a phone, and Wilson et al. [51] showed that mobile phone users had a greater rate of rear-end collisions.

The style of traffic offenses of mobile phone users suggests that they are generally more risky drivers. These differences reflect lifestyles, attitudes and personality factors. It is important to consider these factors in assessing the direct risk attributed to the use of mobile phones [51].

\section{MATERIAL AND METHODS}

Experimental driving tests were performed in order to determine the reaction of the driver in controlling the car, and evaluate the impact of speaking on a phone. The vehicle destabilized when passing through the plate moving in the transverse direction (Photo 1), which causes the slip to the rear axle of the car. When the water is sprayed under the special driving coating with adhesion coefficient $\mu$, it is reduced to 0.2 . The driver's response was determined by the time difference between the moment of the plate activation and the beginning moment of turning the steering wheel.

Corrsys-Datron sensors from Kistel group were used for identifying the moments for calculation of driver's reaction. Inertia measurement unit (IMU) with triaxle accelerometer and gyroscope was used for detection of vehicle destabilization moment and Kistler RV-4 sensor was used for detection of steering moment. Data acquisition systems DAS-3 from Corrsys-Datron fixed measurements with frequency of $100 \mathrm{~Hz}$. Toyota Prius with electronic continuously variable transmission (e-CVT) was used for easy vehicle control. 

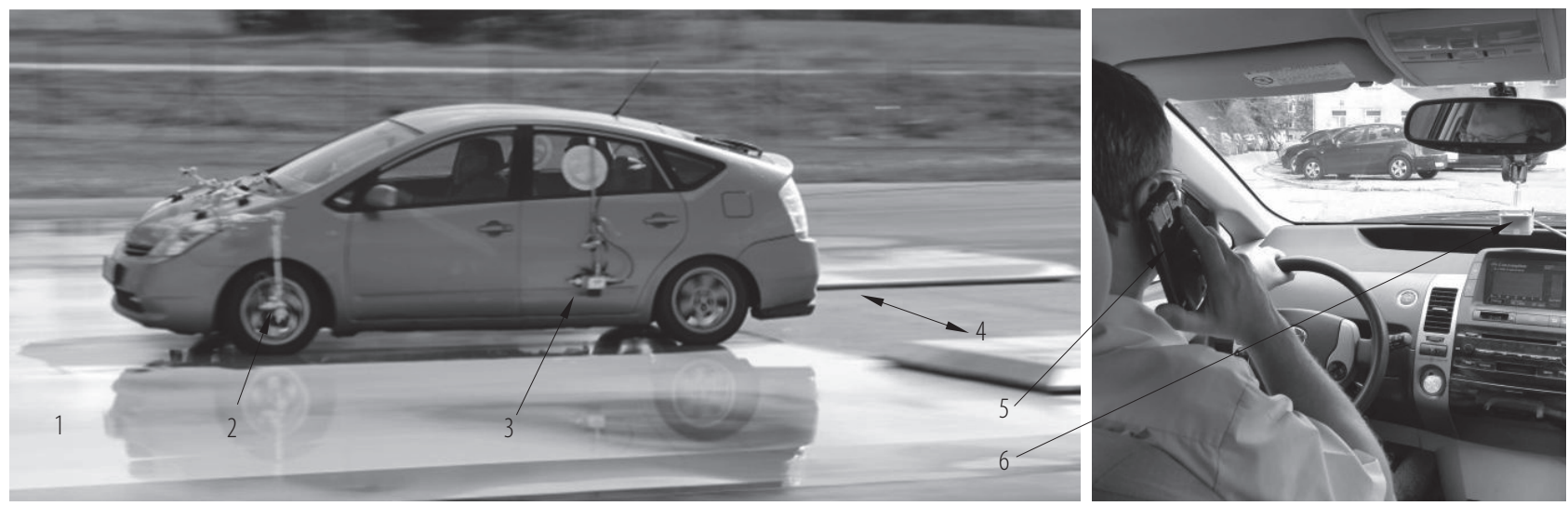

1 - slip pavement; 2 - steering angle sensor; 3 - speed and sideslip angle sensor; 4 - moving plate; 5 - phone cell; 6 - body yaw rate sensor.

Photo 1. Experimental conditions in the study of a driver's reaction time using a cell phone in the case of the vehicle stabilization task

An example of moments' identification from TurboLab 6.0 software is shown in the Figure 1. Determination of the vehicle body sideslip angle [3] was also carried out for evaluation of vehicle stability and slip size.

Every driver performed test runs in 2 stages: the first, normal driving - with both hands (baseline), the second stage was speaking on a phone without a headset, i.e., driving with one hand and holding a phone to the ear (handheld). The drivers participating in the study were given time to get used to the vehicle and to the destabilizing plate.

Fifty-six non-professional drivers, who had valid medical examination certificates and whose working/rest routine corresponded to the daily routine, participated in the tests. These participants drove in the city on a daily basis and each of them spoke on the phone while driving (without a headset). Around $80 \%$ of them got into a bigger or smaller technical accident when the vehicles were only somewhat damaged. Additional information about the study participants is presented in the Table 1.

The horizontally moving plate destabilizing the vehicle may move in 4 basic modes which vary in the transverse plate speed and the movement speed. The plate movement was compatible with the vehicle category, as trucks and buses may also drive on a special track. Several test runs were performed before the tests. Then, the optimal mode of plate movement and the vehicle speed, which must be as close as possible to $35 \mathrm{~km} / \mathrm{h}$ when driving over the plate, were chosen.

The examination of the value distribution fields of the driver reaction time (Figure 2) shows a clear increase in the reaction time when the vehicle is operated by holding a steering wheel with one hand (speaking on a mobile phone).

The Figure 2 shows that when driving with one hand and speaking on a phone, the quantile field of the reaction

Table 1. Characteristics of respondents in the study of a driver's reaction time using a cell phone in the case of the vehicle stabilization task

\begin{tabular}{lcrr}
\hline \multicolumn{1}{c}{ Characteristics } & \multicolumn{1}{c}{ M \pm SD } & Min. & Max \\
\hline Driver's age [years] & $34.56 \pm 9.42$ & 24 & 49 \\
Driving experience [years] & $16.44 \pm 9.45$ & 6 & 31 \\
Distance driven in a typical year [km] & $14889.00 \pm 3951.10$ & 9000 & 20000 \\
\hline
\end{tabular}

$\mathrm{M}$ - mean; min - minimal value; max - maximal value; $\mathrm{SD}$ - standard deviation. 

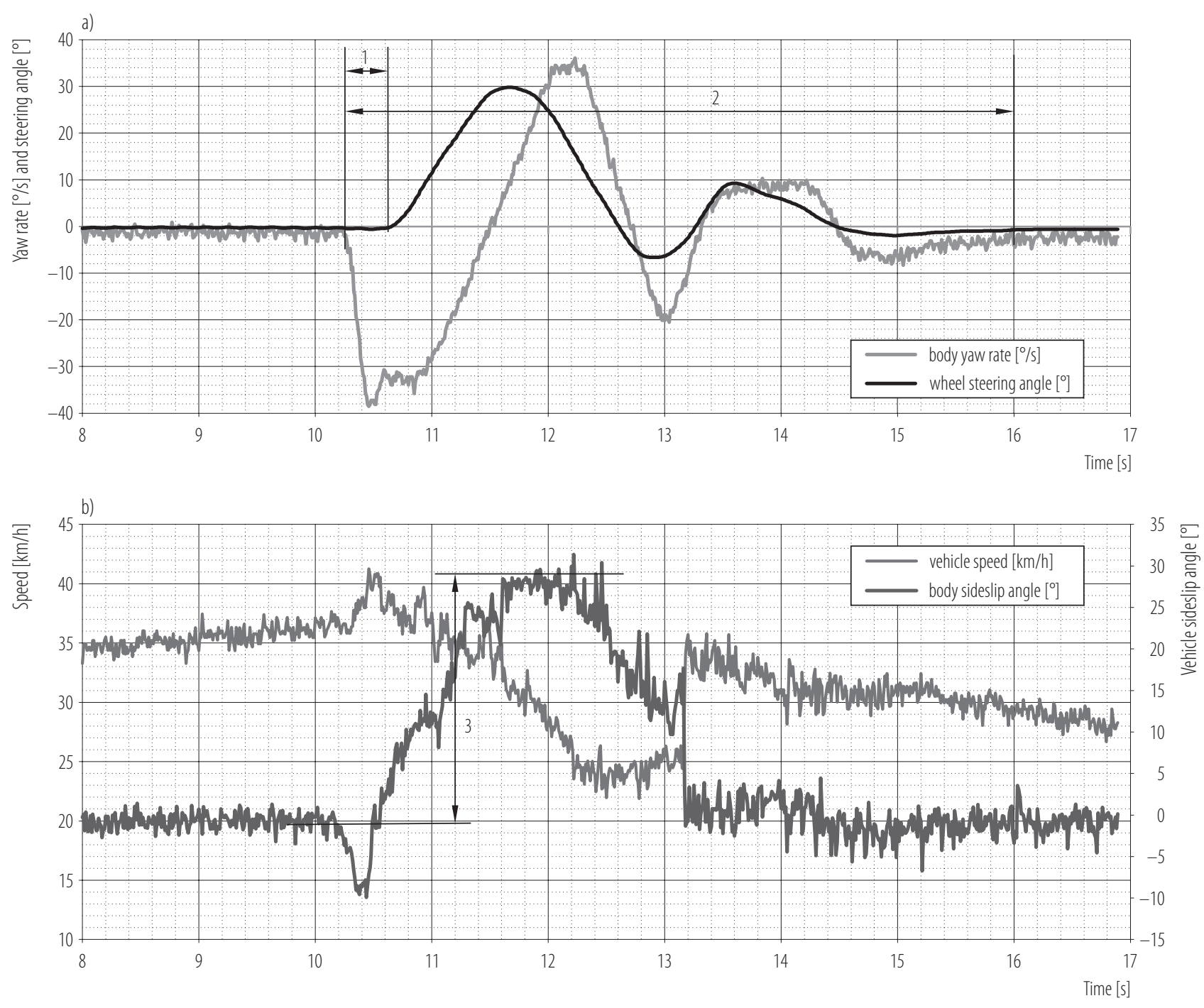

1 - driver's reaction time according to steering; 2 - period of vehicle stabilization; 3 - vehicle slip size.

Fig. 1. Characteristics of experimental procedure for estimation of driver and vehicle response: a) driver's reaction time and vehicle stabilization period, b) vehicle speed and sideslip angle

time, compared with driving with both hands, increases by about $36 \%$. The reaction time quintile field when driving with both hands totals $0.14 \mathrm{~s}$ and driving with one hand (speaking on a phone) $-0.22 \mathrm{~s}$. Thus, the reaction times' dispersal fields when driving with one hand inevitably increase.

In the case of driving with one hand, the quantile branch range increases by 1.3 times - up to nearly $0.56 \mathrm{~s}$ compared to $0.43 \mathrm{~s}$ for driving with both hands (Figure 2). As it can be seen in the same figure, in both cases of testing, the minimum and maximum driver's reaction time values coincide with the apexes of the quantile branches.

In the examination of those test cases, it is appropriate to look at the distribution fields of the values of vehicle speed before the test, because speed is an important parameter to maintain the test conditions as uniform as possible. This distribution is presented in the Figure 3. The figure shows that while driving with both hands, 


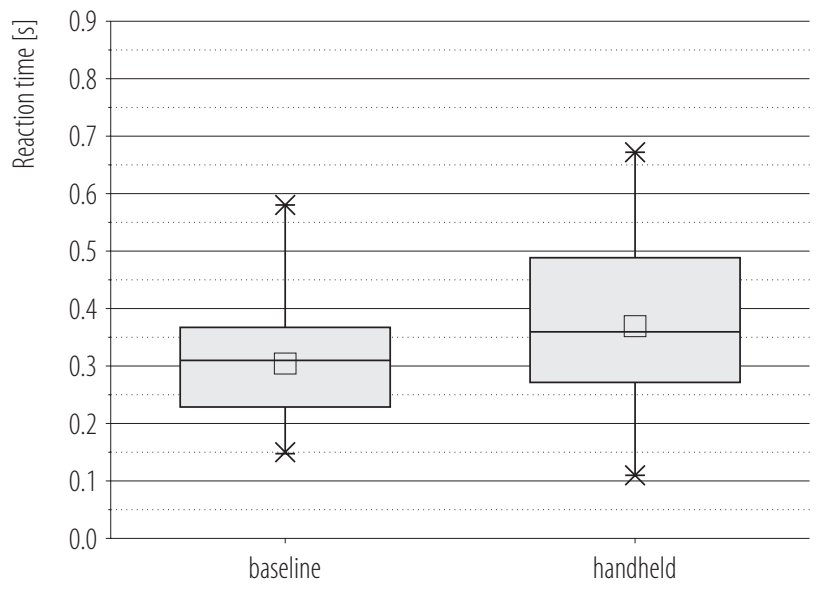

Baseline - driving with both hands.

Handheld - driving with one hand and speaking on a mobile phone.

Fig. 2. Drivers' reaction time depending on using a cell phone in the case of the vehicle stabilization task

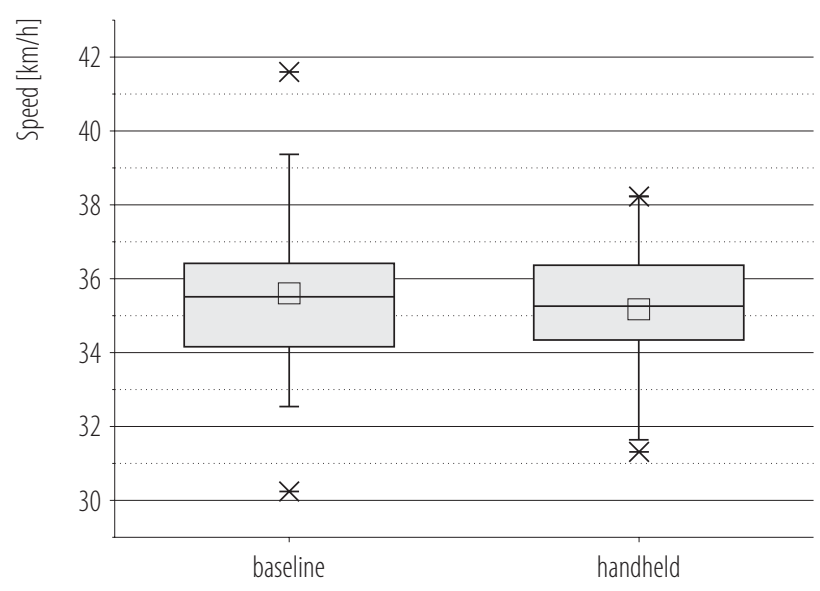

Explanations as in Figure 2.

Fig. 3. Vehicle movement speed before experimental tests

the quintile field of speed values, compared with the case of driving with one hand (speaking on a phone), is higher by about $12.7 \%$ : the quintile field of values of speeds when driving with both hands is $2.27 \mathrm{~km} / \mathrm{h}$ and driving with one hand (speaking on a phone) $1.98 \mathrm{~km} / \mathrm{h}$. By comparing the medians of speed values in this graph we can see that in the case of driving with one hand (speaking on a phone) the driving speeds are decreased as compared to the case of driving with both hands. The difference of median values is about $0.6 \%$. The average movement speed is also lower by $0.9 \%$ when driving with one hand (speaking on a phone).

The quintile branch ranges in both test cases are similar, and total about $7 \mathrm{~km} / \mathrm{h}$ but we can see that when speaking on a phone, there is a tendency to reduce the speed before the test as compared to the case when driving with both hands (Figure 3).

This figure shows that while driving with one hand and speaking on a phone, the minimum and maximum speed values before the test coincide with the apexes of the quantile branches. When driving with both hands, the said values are significantly distant from the quintile branch ranges, and the difference between the maximum and minimum values is about $11 \mathrm{~km} / \mathrm{h}$. This could be explained by the fact that when driving with one hand and speaking on a phone, drivers before the tests attempted to choose a lower driving speed, thus trying to compensate for the shortage of concentration of attention, and driving with one hand.

\section{RESULTS}

The analysis of experimental test results described above in this section is performed in order to determine what theoretical distribution law describes the reaction time values of the tested drivers, when speaking and not speaking on a mobile phone (driving with one hand). Once specific patterns are found, we can perform the likelihood of the delay of drivers' actions in controlling the vehicle (whether speaking or not speaking on a phone) under the identified reaction time. Conversely, if we have the identified likelihood of the delay of drivers' actions in controlling the car, we can predict the likely reaction time.

Experimental tests were analyzed with the mathematical statistics computer software Statistica, which evaluates the values of the mathematical average $t$, standard square deviation $(\sigma)$, and the suitability of the derived theoretical distribution law for the analysis of experi- 
mental data, checking with the Pearson compatibility criterion $\mathrm{Chi}^{2}$ [57].

First of all, the mathematical statistical model is based on the case of experimental studies, when the reaction time of the tested drivers is determined when they do not speak on a mobile phone (both driver's hands are on a steering wheel). The Figure 4 shows the formats of the created differential statistical model (relative frequency $f(t)$ as a function of reaction time) and the integral statistical model (total relative frequency $\mathrm{F}(\mathrm{t})$ as a function of reaction time).

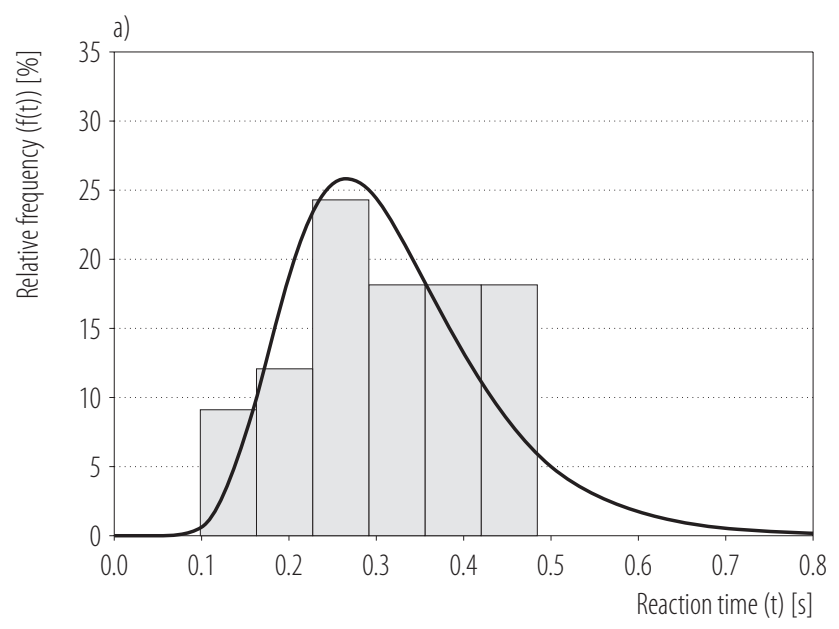

It is seen that the experimental test results are distributed according to the pattern similar to the normal log-distribution law, when the theoretical functions (smooth curve) mode of the differential statistical model is shifted to the left (Figure 4a).

The mathematical statistical model made in the other stage of the experimental test analysis is based on the case when the reaction time of the analyzed drivers is determined when they speak on a mobile phone (driving with one hand). The Figure 5 shows the formats of the corre-

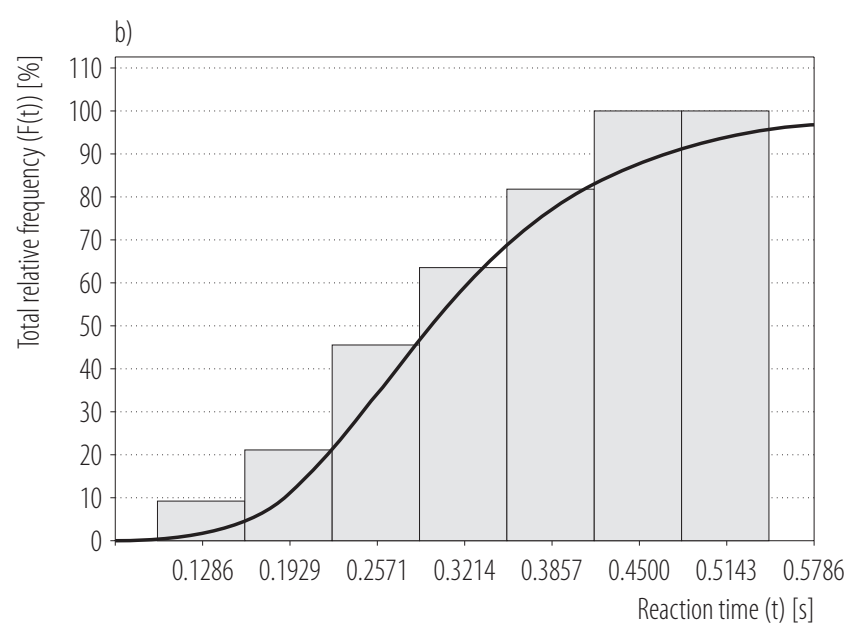

Fig. 4. Drivers' conditions by reaction time - experimental tests of not speaking on a mobile phone when driving: a) differential statistical model, b) integral statistical model
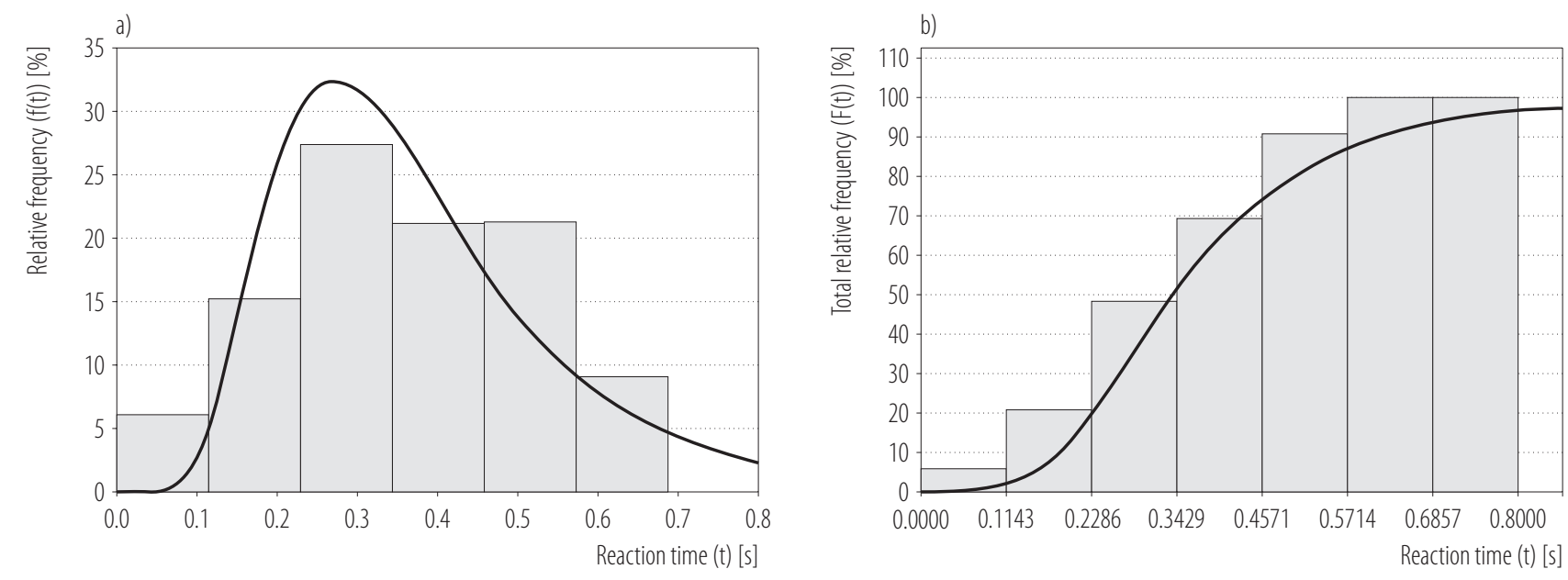

Fig. 5. Drivers' conditions by reaction time - experimental tests when speaking on a mobile phone when driving: a) differential statistical model, b) integral statistical model 
sponding dependencies. In this case, as in the previously discussed case, the experimental test results are distributed according to the pattern similar to the normal logdistribution law.

It is important to note that in these figures the relative frequency $f(t)$ and the cumulative relative frequency $F(t)$ may be expressed in probabilistic parameters, i.e., the fixed reaction time values in the corresponding range may be defined with a likelihood of a certain occurrence of this value. Function $\mathrm{f}(\mathrm{t})$ may be described as the probability distribution function of reaction times over the entire measurement range, and $\mathrm{F}(\mathrm{t})$ - as summarization of the same probabilities $\mathrm{f}(\mathrm{t})$ consistently in each interval.

In examining these dependencies, it is appropriate to analyze the said functions in cases where drivers do not speak, and when they speak on a phone - to assess the main differences, and the resulting causes.

In analyzing the obtained graphical expressions of the differential statistical model (Figure 4a, Figure 5a) we can see the lesser dispersion of the reaction time values (and corresponding probabilities) when driving with both hands in respect of the mathematical average. In this case, in the analyzed data distribution (Figure 4a), the reaction time values $<0.1$ and $>0.5$ s do not comprise even $5 \%$. Meanwhile, in the case of driving while speaking on a phone (Figure 5a) we can see that the reaction time values in the date dispersion range from $<0.1 \mathrm{~s}$ to almost $0.7 \mathrm{~s}$, and the maximum value of relative frequency is in excess of $30 \%$ (when driving in both hands, the maximum value is about $25 \%$ ).

The emergence of shorter reaction times may be explained by the fact that the drivers already knew the moment at which the vehicle rear axle would be shifted, and regardless of speaking on a phone, they concentrated for the upcoming manoeuvre. Longer reaction time values mean that, however, in further experimental tests, drivers were not able to fully maintain the proper concentration (speaking on a mobile phone is a powerful distraction factor), and proceeded to do more and rougher errors. Therefore, the reaction time was becoming inevitably longer (Figure 5a). Similarly, Figure 4a shows that when driving with both hands and being concentrated (not speaking on a phone), the dissemination of the reaction time $0.3-0.5 \mathrm{~s}$ is stable - in the range of 3 intervals its value is about $17 \%$. Then, where we have the phone factor (driving with one hand), data distribution takes on the form of greater dispersion (Figure 5a).

The Figure 4a and 5a also show that based on the mathematical statistical models, the values of mathematical averages are the same as compared with those calculated according to the experimental data (i.e., $0.319 \mathrm{~s}$ when driving with both hands and about $0.371 \mathrm{~s}$, when speaking on a phone), which reaffirms the adequacy of obtained models for applying them in calculating the likelihood of the driver's action delays in controlling the vehicle (not speaking/speaking on a phone), under the fixed reaction time, etc.

The examination of integrated statistical models (Figure $4 \mathrm{~b}$, Figure 5b) shows that with the increase in the drivers' reaction time, the likelihood of a driver's action delays in controlling the vehicle is growing (if the relative frequency $\mathrm{f}(\mathrm{t})$ is regarded as a probability). For the case of driving with both hands (the average reaction time value $0.319 \mathrm{~s}$ ), then based on the Figure $5 \mathrm{~b}$ (smooth curve) we can see that the likelihood of the driver's action delays in controlling the vehicle is about 0.5 (relative frequency value $\mathrm{F}(\mathrm{t})$ is about $50 \%$ ). Meanwhile, when speaking on a phone when driving (Figure 5b), this likelihood increases to nearly 0.6 (relative frequency $\mathrm{F}(\mathrm{t})$ value is about $60 \%$ ), which indicates a negative impact of a mobile phone on safe driving. The same is true for other ranges (intervals) of reaction time values. It is important to mention that when speaking on a phone, and when the reaction time is already about $0.5 \mathrm{~s}$, the likelihood of delay of the driver's actions in controlling a vehicle increases very significantly and exceeds 0.8 (the relative frequency $F(t)$ value is over $80 \%$ ). This means that at relatively small increase in 
reaction time (for example, from $0.2 \mathrm{~s}$ to $0.5 \mathrm{~s}$ ), the likelihood of delay of the driver's actions in controlling the vehicle increases from about 0.15 to 0.8 or more. Hence, with the reaction time of $0.5 \mathrm{~s}$, there is a high probability that the driver's actions will be significantly late in controlling a car.

According to the Figure $4 \mathrm{~b}$ and $5 \mathrm{~b}$ we can make reverse predictions, i.e., in both cases (driving with both hands and speaking on a phone) we can determine what the likely value of the driver's reaction time is at a certain probability of delay in the driver's actions in controlling the car.

\section{CONCLUSIONS}

The use of mobile phones is a potential distraction factor, particularly for certain groups of drivers. A possible line for the development of subsequent studies is the identification of these groups of hypersusceptible subjects. The above-mentioned studies may suggest that the lack of sleep, insomnia, obstructive sleep apnea (OSA), and drowsiness could be propensity factors.

However, the risk of using the phone depends on drivers' characteristics, traits and attitudes that affect the level of their experienced dangers, and the intensity of using mobile phones and driving.

The use of a mobile phone for more than $50 \mathrm{~min} / \mathrm{month}$ is associated with the 5.59 times greater risk of collisions as compared to persons who do not use a mobile phone at all. Drivers using a mobile phone up to $10 \mathrm{~min}$ before the traffic accident were linked to 4 times (4.1 times) higher accident probability.

The following conclusions may be made after performing the analysis of the effects on the driver reaction while speaking on a phone, summarizing the results of the experimental test and performing the statistical assessment of results:

- Speaking on a phone while driving increases the driver's reaction time and mental workload, and changes the driver's visual overview ability and understanding of the situation. Scattering of the driving speed val- ues during the experiment increases by $12.7 \%$, which makes it possible to conclude that drivers compensate for the loss of their working capacity by increasing the security limits - reducing the speed.

- When stabilizing a vehicle movement, the complex reaction time of a vehicle driver speaking on a mobile phone is increased by $18.1 \%$ as compared with the conventional driving by a driver not speaking on a phone and this reduces the possibility of controlling the vehicle following its sudden slip (destabilization).

- To determine the complex driver reaction under the clear vehicle destabilization moment, it is appropriate to analyze the time interval between the destabilization and the start of the driver's responsive action with the steering wheel.

- The relatively short duration of reaction is obtained when the driver knew the moment when the measurement would take place but it does not prevent from identifying the negative factor chosen for the test - the impact of speaking on a phone.

- In the analyzed cases, driving with both hands (not speaking on a phone) and when driving with one hand and speaking on a phone, the experimental test results (probabilities corresponding to the reaction time values) are distributed according to the pattern close to the normal log distribution law. This distribution, as compared to normal distribution, is unsymmetrical, which in this case means that higher probability of the appearance (0.15-0.3 s range) of shorter reaction times compared with the entire range of dispersion of all reaction times $(0-0.7 \mathrm{~s})$ is noted in differential statistical models.

- Differential statistical models have shown that smaller dissemination of reaction times and the corresponding likelihood values in respect of the mathematical average (approximately $\pm 0.2 \mathrm{~s}$ ) was obtained when driving with both hands, as compared with the case of driving while speaking on a phone (about $\pm 0.3 \mathrm{~s}$ ). This is ex- 
plained by the negative impact of speaking on a phone on the operation of the car.

- Integral statistical models have helped to identify:

1. When driving and speaking on a phone, the probability of delay in the driver's actions in controlling the vehicle increases from $0.5 \mathrm{~s}$ to $0.6 \mathrm{~s}$ as compared to the case of driving and not speaking on a phone. These values correspond to the average reaction time values in the corresponding case of tests;

2. When speaking on a phone and driving, the reaction time increases to $0.5 \mathrm{~s}$ and more, therefore, the probability of the driver's actions in controlling the vehicle increases and may exceed $0.8 \mathrm{~s}$. This means that at relatively small increase in reaction time $(0.2 \mathrm{~s}$ to $0.5 \mathrm{~s})$, there is a high ( $0.8 \mathrm{~s}$ and above) probability that the driver's actions in controlling the vehicle will be severely delayed.

\section{REFERENCES}

1. Bogdanovičius Z, Pikūnas A, Pečeliūnas R. [Road users psychophysiology]. Vilnius: Technika; 2007. p. 96. Lithuanian.

2. Zaranka J, Pečeliūnas R, Matijošius J. Analysis of the influence of fatigue on passenger transport drivers' performance capacity. Transport. 2012;27(4):351-6, https://doi.org/10.3846/ 16484142.2012.750625.

3. Zaranka J. [The impact of motor vehicle driver behaviour factors on traffic safety] [doctoral dissertation]. Vilnius: Technika; 2012. p. 102. Lithuanian.

4. Davenne D, Lericollais R, Sagaspec P, Taillard J, Gauthiera A, Espiéc $\mathrm{S}$, et al. Reliability of simulator driving tool for evaluation of sleepiness, fatigue and driving performance. Accid Anal Prev. 2012;45:677-82, https://doi.org/10.1016/j.aap.2011.09.046.

5. Garbarino S, Lanteri P, Moro V, Pernigo S, Magnavita N, Chiorri $\mathrm{C}$, et al. Dynamics of emotional unavoidable error monitoring in stress and no stress Police Special Force: An event-related potential associated with error processing (ERN) investigation. Clin Neurophysiol. 2013;124(11):e196, https://doi.org/10.1016/j.clinph.2013.06.060.
6. Makowiec-Dąbrowska T, Bortkiewicz A, Siedlecka J, Gadzicka E. [Effect of fatigue on the fitness to drive]. Med Pr. 2011;62(3):281-90. Polish.

7. Garbarino S, Nobili L, Costa G, editors. Sleepiness and human impact assessment. New York: Springer; 2014, https:// doi.org/10.1007/978-88-470-5388-5.

8. Garbarino S, Gelsomino G, Magnavita N. Sleepiness, safety and transport. J Ergonomics 2014;S3:003, https://doi.org/ 10.4172/2165-7556.S3-003.

9. Siedlecka J, Bortkiewicz A. [Driving simulators in risk assessment of traffic accident among drivers with obstructive sleep apnea]. Med Pr. 2012;63(2):229-36. Polish.

10. Garbarino S, Durando P, Guglielmi O, Dini G, Bersi F, Fornarino S, et al. Sleep apnea, sleep debt and daytime sleepiness are independently associated with road accidents. A cross-sectional study on truck drivers. PLoS One. 2016; 11(11):e0166262, https://doi.org/10.1371/journal.pone.0166262.

11. Chiorri C, Garbarino S, Bracco F, Magnavita N. Personality traits moderate the effect of workload sources on perceived workload in flying column police officers. Front Psychol. 2015;6:1835, https://doi.org/10.3389/fpsyg.2015.01835.

12. Zaranka J, Guzek M, Pečeliūnas R, Bogdanovičius Z, Matijošius J. Comparative research on the optical and acoustic psychomotor reaction of professional drivers. In: Bogdevičius M, Lozia Z, Pshinko A, editors. Transbaltica 2013: Proceedings of the 8th International Scientific Conference; 2013 May 9-10; Vilnius, Lithuania. Vilnius: Technika; 2013. p. 277-81, https://doi.org/10.3846/transbaltica2013.059.

13. Muttray A, Breitinger A, Goetze E, SchnuppT, Geissler B, KaufmannT, et al. Further development of a commercial driving simulation for research in occupational medicine. Int J Occup Med Environ Health. 2013;26(6):949-65, https:// doi.org/10.2478/s13382-013-0164-5.

14. Papadakaki M, Tzamalouka G, Gnardellis Ch, Lajunen TJ, Chliaoutakis J. Driving performance while using a mobile phone: A simulation study of Greek professional drivers. 
Transp Res Part F Traffic Psychol Behav. 2016;38:164-70, https://doi.org/10.1016/j.trf.2016.02.006.

15. Choudhary P, Velaga NR. Analysis of vehicle-based lateral performance measures during distracted driving due to phone use. Transp Res Part F Traffic Psychol Behav. 2017;44:120-33, https://doi.org/10.1016/j.trf.2016.11.002.

16. Zajdel R, Zajdel J, Śmigielski J, Nowak D. Cell phone ringtone, but not landline phone ringtone, affects complex reaction time. Int J Occup Med Environ Health. 2013;26(1):10212, https://doi.org/10.2478/s13382-013-0080-8.

17. White KM, Hyde MK, Walsh SP, Watson B. Mobile phone use while driving: An investigation of the beliefs influencing drivers' hands-free and hand-held mobile phone use. Transp Res Part F Traffic Psychol Behav. 2010;13(1):9-20, https:// doi.org/10.1016/j.trf.2009.09.004.

18. Haigney DE, Taylor RG, Westerman SJ. Concurrent mobile (cellular) phone use and driving performance: Task demand characteristics and compensatory processes. Transp Res Part F Traffic Psychol Behav. 2000;3(3):113-21, https:/doi. org/10.1016/S1369-8478(00)00020-6.

19. Burns PC, Parkes A, Burton S, Smith RK, Burch D. How dangerous is driving with a mobile phone? Benchmarking the impairment to alcohol report. Report No. TRL 547. Crowthorne: Transport Research Laboratory; 2002.

20. Alm H, Nilsson L. The effect of a mobile telephone task on driver behaviour in a vehicle following situation. Accid Anal Prev. 1995;27(5):707-15, https://doi.org/10.1016/00014575(95)00026-V.

21. Törnros J, Bolling A. Mobile phone use - Effects of handheld and handsfree phones on driving performance. Accid Anal Prev. 2005;37(5):902-9, https://doi.org/10.1016/j.aap. 2005.04.007.

22. Fairclough SH, Ashby MC, Roos T, Parkes AM. Effects of handsfree telephone use on driving behaviour. Proceedings of the 24th ISATA International Symposium on Automotive Technology and Automation, 1991, p. 403-9.

23. Pachiaudi G, Morgillo F, Deleurence P, Guilhon V. [Handsfree phone use: Impact of the communication on the driving task]. Lyon: INRETS - National Institute for Transport and Safety Research; 1996 Nov. Report No.: 212. French.

24. Matthews R, Legg S, Charlton S. The effect of cell phone type on drivers subjective workload during concurrent driving and conversing. Accid Anal Prev. 2003;35(4):451-7, https://doi.org/10.1016/S0001-4575(02)00023-4.

25. Chapon A, Bruyas MP. [Consequences of NTIC use while driving - The COUNTIC Project]. Lyon: INRETS - National Institute for Transport and Safety Research; 2004. Report No.: 82. French.

26. Harbluk JL, Noy YI, Eizenman M. The impact of cognitive distraction on driver visual behaviour and vehicle control, TP 13889E. Canada: Transport; 2002. p. 26.

27. Nunes L, Recarte MA. Cognitive demands of hands-freephone conversation while driving. Transp Res F Traffic Psychol Behav. 2002;5(2):133-44, https://doi.org/10.1016/ S1369-8478(02)00012-8.

28. Recarte MA, Nunes LM. Effects of verbal and spatial imagery tasks on eye fixations while driving. J Exp Psychol Appl. 2000;6(1):31-43, https://doi.org/10.1037/1076-898X.6.1.31.

29. Atchley P, Dressel J. Conversation limits the functional field of view. Hum Factors. 2004;46(4):664-73, https://doi. org/10.1518/hfes.46.4.664.56808.

30. Strayer DL, Drews FA, Johnston WA. Cell phone induced failures of visual attention during simulated driving. J Exp Psychol Appl. 2003;9(1):23-32, https://doi.org/10.1037/1076898X.9.1.23.

31. Richard CM, Wright RD, Ee C, Prime SL, Shimizu Y, Vavrik J. Effect of a concurrent auditory task on visual search performance in a driving-related image-flicker task. Hum Factors. 2002;44(1):108-19, https://doi.org/10. 1518/0018720024494874.

32. McCarley JS, Vais M, Pringle H, Kramer AF, Irwin DE, Strayer DL. Conversation disrupts change detection in complex traffic scenes. Hum Factors. 2004;46(3):424-36, https:// doi.org/10.1518/hfes.46.3.424.50394.

33. McPhee LC, Scialfa CT, Dennis WM, Ho G, Caird JK. Age differences in visual search for traffic signs during a 
simulated conversation? Hum Factors. 2004;46(4):674-85, https://doi.org/10.1518/hfes.46.4.674.56817.

34. Parkes A, Hooijmeijer V. The influence of the use of mobile phones on driver attention awareness. Final report. Rockville: Driver distraction Internet forum, NHTSA, National Highway Traffic Safety Administration; 2000 Nov. Contract No.: DTNH22-99-D-07005.

35. Bailly B, Bellet T, Goupil C. Drivers' mental representations: Experimental study and training perspectives. In: Dorn L, editor. Driver behaviour and training. Ashgate: England; 2003. p. 397-405.

36. Gugerty L, Rakauskas M, Brooks J. Effects of remote and in-person verbal interactions on verbalization rates and attention to dynamic spatial scenes. Accid Anal Prev. 2004; 36(6):1029-43, https://doi.org/10.1016/j.aap.2003.12.002.

37. Drews FA, Pasupathi M, Strayer DL. Passenger and cellphone conversations in simulated driving. In: Human Factors and Ergonomics Society. HFES 2004: proceedings of the Human Factors and Ergonomics Society 48th Annual Meeting: September 20-24, 2004, New Orleans, Louisiana. New Orleans, Louisiana. Santa Monica, CA: The Society; 2210-2, https://doi.org/10.1177/154193120404801901.

38. Caird JK, Johnston KA, Willness CR, Asbridge M, Steel P. A meta-analysis of the effects of texting on driving. Accid Anal Prev. 2014;71:311-8, https://doi.org/10.1016/j.aap. 2014.06.005.

39. He J, Ellis J, Choi W, Wang P. Driving while reading using google glass versus using a smartphone: Which is more distracting to driving performance? In: University of Iowa. Proceedings of the 8th International Driving Symposium on Human Factors in Driver Assessment, Training and Vehicle Design; 2015 June 22-25; Salt Lake City, Utah. Iowa City, IA: The University, Public Policy Center; 2015. p. $275-81$.

40. Hahn RW, Prieger JE. The impact of driver cell phone use on accidents. AEI-Brookings Joint Center Working Paper No. 04-14, https://doi.org/10.2139/ssrn.568303.
41. Benedetto A, Calvi A, D’Amico F. Effects of mobile telephone tasks on driving performance: A driving simulator study. Adv Transport Stud Int J Sect A. 2012;26:29-44.

42. Things That Think [Internet]. Cambridge, Massachusetts, US: The Media Lab; c. 1995-2014 [cited 2017 Sep 12]. Marinova M, Devereaux J, Hansman RJ. Experimental studies of driver cognitive distraction caused by cell phone use. Prepared for: Transportation Research Part F. Available from: http://ttt. media.mit.edu/impact/marinovadeverauxhans.pdf.

43. Nurullah AS, Thomas J, Vakilian F. The prevalence of cell phone use while driving in a Canadian province. Transp Res Part F Traffic Psychol Behav. 2013;19:52-62, https://doi.org/ 10.1016/j.trf.2013.03.006.

44. Woo TH, Lin J. Influence of mobile phone use while driving: The experience in Taiwan. IATSS Res. 2001;25(2):15-9, https://doi.org/10.1016/S0386-1112(14)60066-2.

45. Strayer DL, Drews FA, Crouch DJ. A comparison of the cell phone driver and the drunk driver. AEI-Brookings Joint Center Working Paper No. 04-13, https://doi.org/10.2139/ ssrn.570222.

46. Przybyla J, Zhou X. Cell phone use while driving: A literature review and recommendations [Internet]. Salt Lake City, UT: University of Utah; 2008 [cited 2017 Sep 12]. Available from: http://www.civil.utah.edu/ zhou/cell_phone_and_distracted_driver.pdf.

47. Walsh SP, White KM, Hyde MK, Watson B. Dialling and driving: Factors influencing intentions to use a mobile phone while driving. Accid Anal Prev. 2008;40(6):1893-900, https:// doi.org/10.1016/j.aap.2008.07.005.

48. Bhargava S, Pathania VS. Driving under the (cellular) influence. Am Econ J Econ Policy. 2013;5(3):92-125, https://doi. org/10.1257/pol.5.3.92.

49. Laberge-Nadeau C, Maag U, Bellavance F, Desjardins D, Messier S, Saïdi A. [Cell phones and the risk of accidents]. Canada: Université de Montréal; 2001. French.

50. Laberge-Nadeau C, Maag U, Bellavance F, Lapierre S, Desjardins D, Messier S, et al. Wireless telephones and the 
risk of road crasches. Accid Anal Prev. 2003;35(4):649-60, https://doi.org/10.1016/S0001-4575(02)00043-X.

51. Wilson J, Fang M, Wiggins S, Cooper P. Collision and violation involvement of drivers who use cellular telephones. Traffic Inj Prev. 2003;4(1):45-52, https://doi. org/10.1080/15389580309851.

52. Violanti JM, Marshall JR. Cellular phone and traffic accidents: An epidemiological approach. Accid Anal Prev. 1996;28(2):265-70, https://doi.org/10.1016/0001-4575(95) $00070-4$.
53. Redelmeier DA, Tibshirani RJ. Association between cellular telephone calls and motor vehicle collisions. N Eng J Med. 1997;336(7):453-8, https://doi.org/10.1056/NEJM199 702133360701.

54. McEvoy SP, Stevenson MR, McCartt AT, Woodward M, Haworth C, Palamara P, et al. Role of mobile phones in motor vehicle crashes resulting in hospital attendance: A casecrossover study. Br Med J. 2005;331(7514):428-32, https:// doi.org/10.1136/bmj.38537.397512.55.

This work is available in Open Access model and licensed under a Creative Commons Attribution-NonCommercial 3.0 Poland License - http://creativecommons.org/ licenses/by-nc/3.0/pl/deed.en. 